\title{
A Educação na Sociedade Informacional anotações provenientes de uma pesquisa de natureza filosófica
}

\author{
Gilberto Lacerda Santos \\ Raquel de Almeida Moraes \\ Professores Associados da Universidade de Brasília
}

\section{Resumo}

Este texto apresenta uma reflexão sobre a natureza da educação na atual fase da sociedade capitalista onde a informática emerge como a tecnologia preponderante na escola e na sociedade a ponto de influir na sua constituição como moeda de troca dos valores materiais e simbólicos. Utilizando a metodologia da pesquisa bibliográfica, o trabalho, em seu cerne, relata uma investigação de natureza filosófica que aborda as seguintes questões: Como articular uma abordagem filosófica desse movimento de introdução das TICE na escola, de modo que possamos melhor entendê-lo? E, mais amplamente, como compreender e situar a educação nessa Sociedade Informacional emergente? Como conclusão, o texto assinala que são necessárias ações multidirecionadas, que conjuguem tanto os "de baixo", nas palavras do saudoso Florestan Fernandes, como os de cima, a saber, os responsáveis pela elaboração e condução das políticas públicas para o setor, formando as bases de um real processo decisório. Só assim será possível o uso de tecnologias em prol de uma maior participação do indivíduo e em prol do fortalecimento de uma educação socialmente responsável e cidadã.

Palavras-chave: educação; projeto político-pedagógico; sociedade informacional.

\begin{abstract}
This text presents a reflection on the nature of education in the current phase of capitalist society where computing emerges as the predominant point of influence in its constitution as a bargaining chip of material, technological and symbolic values. Using the methodology of the literature search, the work addresses the following questions: How to articulate a philosophical approach of this movement for the introduction of ICET in school? And, more broadly, how to understand and situate education in this emerging informational society? In conclusion, the text points out that multiple actions are necessary, which combine both people interests and political interests, forming the foundations of a real decision-making process. Uniquely by this, the use of technology in education can promote greater participation of the individual and a socially responsible and civic education.
\end{abstract}

Keywords: Education; Political-Pedagogical Project; Informational Society.

Filosofia e Educação - ISSN 1984-9605

Volume 6, Número 2 - Junho de 2014 
Introdução: a educação mediada por tecnologias de informação

ob todos os aspectos, a educação mediada pelas novas tecnologias 1 de informação, comunicação e expressão, a que chamaremos de TICE, tem um potencial inquestionável, que gradualmente vai sendo desvendado por pesquisadores de todo o mundo, relacionado não apenas à manipulação de recursos tecnológicos que permeiam todas as áreas do conhecimento e que estão revolucionando a sociedade como um todo, mas também à instauração de uma cultura profundamente baseada no livre fluxo de ideias e no acesso feérico à informação. Desde meados dos anos 70, as TICE vêm adquirindo uma importância cada vez maior no campo da educação, tendo em vista o rápido avanço tecnológico e o advento da chamada Sociedade Informacional, termo empregado pelo canadense Don Tapscott para designar a Era da Inteligência em Rede (TAPSCOTT, 1997). É, portanto, de fundamental importância que educadores de todos os níveis de ensino preparem-se para um novo modus operandi, para trabalharem de acordo com novos paradigmas educacionais relacionados com a exploração pedagógica dessas mídias, como propõe Letti (2014).

As primeiras iniciativas brasileiras no campo da integração pedagógica das TICE datam da década de 70, quando algumas experiências americanas de Informática Educativa foram implantadas no país. Naquela época, as ações nesse campo, assim como todas as iniciativas relacionadas com a informática, foram situadas no âmbito da Secretaria Especial de Informática da Presidência da República e eram consideradas fatores de segurança e de desenvolvimento nacionais pelos governos militares que conduziam o país. A I Conferência Nacional de Tecnologia Aplicada ao Ensino Superior, ocorrida em 1973, foi um marco importante tendo em vista 


\section{pesquisas}

que foi o primeiro espaço em que se discutiu, no Brasil, o uso efetivo do computador na educação. No final da década de 70, centrado na exploração pedagógica do Logo, linguagem de programação com forte apelo construtivista e visual, foi criado o Laboratório de Estudos Cognitivos da Universidade Federal do Rio Grande do Sul, sob a coordenação da Profa. Dra. Léa Fagundes, figura de destaque no desenvolvimento e no avanço da Informática Educativa no Brasil. Considerado como o setor mais importante para a construção de uma modernidade aceitável e própria, capaz de articular o avanço científico e tecnológico com o patrimônio cultural da sociedade e de promover as interações necessárias, a educação foi compreendida, pelo Regime Militar, como a alavanca da informatização de nossa sociedade, condição imprescindível para o ingresso do país no mundo desenvolvido.

Cerca de dez anos mais tarde, em 1982, em pleno período de abertura política e de fim do Regime Militar, o Ministério da Educação começou a articular-se mais amplamente no campo da Informática Educativa, criando programas especiais, instigando a condução de projetos de pesquisa e fomentando um desenvolvimento institucional da área. Iniciativas oriundas da sociedade civil começaram a delimitar o cenário desse setor no Brasil. As iniciativas pioneiras da Universidade Federal do Rio de Janeiro, da Universidade Estadual de Campinas e da Universidade Federal do Rio Grande do Sul, iniciadas a partir de 1973, formaram toda uma geração de pesquisadores que impulsionaram a área no país. A visita de Seymour Papert à Universidade de Campinas, em 1975, alavancou o desenvolvimento de atividades de cooperação com instituições americanas de vanguarda nesse campo e permitiu a criação, em 1983, do atual Núcleo de Informática Educativa. Papert, pesquisador americano discípulo de Piaget, foi um dos criadores da Linguagem Logo, citada anteriormente. 
Em 1981, por iniciativa de uma equipe intersetorial envolvendo técnicos e especialistas da Secretaria Especial de Informática, do Ministério da Educação e do Conselho Nacional de Desenvolvimento Científico e Tecnológico, teve lugar o I Seminário Nacional de Informática na Educação, na Universidade de Brasília, o primeiro grande fórum brasileiro para o estudo da questão. O projeto Educação e Computador (EDUCOM), idealizado a partir das recomendações deste seminário, propiciou a criação de centros-piloto experimentais em Informática Educativa em várias universidades brasileiras e representou a primeira ação oficial, concreta, de levar computadores às escolas públicas do país. Seu objetivo principal foi estimular o desenvolvimento da pesquisa multidisciplinar voltada para a aplicação das tecnologias de informática no processo de ensinoaprendizagem, de modo a proporcionar o desenvolvimento de novas metodologias de ensino, uma aprendizagem mais ativa e significativa e uma educação básica de melhor qualidade. Por meio desse projeto, foram implantados cinco centros de Informática Educativa nas Universidades Federais de Pernambuco, do Rio de Janeiro, de Minas Gerais, do Rio Grande do Sul e na Universidade Estadual de Campinas.

Em 1986, o MEC lançou o Programa de Ação Imediata em Informática na Educação de $1^{\circ}$ e $2^{\circ}$ Graus, cujo objetivo era propiciar a implantação de infraestrutura de suporte para ações e iniciativas no setor, em Secretarias Estaduais de Educação. No âmbito desse programa, foi lançado o I Concurso Nacional de Software Educativo, que se repetiu anualmente, durante vários anos. Igualmente, foi instituído o projeto FORMAR, voltado para a formação em Informática Educativa, em nível de especialização, de professores de todo o país. Uma vez formados, tais professores foram incumbidos da criação dos Centros de Informática 
Educativa das Secretarias Estaduais de Educação, os CIEd.

Em 1987, foi instituído o primeiro sistema brasileiro de formação continuada de professores por meio da tecnologia da informática. Foi o Sistema de Disseminação de informações Tecnológicas Emergentes (SDITE), que respondia a objetivos estratégicos da Secretaria de Ensino Técnico do Ministério da Educação quanto à capacitação do corpo docente das instituições federais de educação tecnológica. O projeto contou com o apoio financeiro da Organização dos Estados Americanos (LACERDA SANTOS, 1996).

Em 1989, durante a realização da Jornada Luso-Latino-Americana de Informática na Educação, em Petrópolis (RJ), foi criada a Sociedade Brasileira de Informática Educativa, iniciativa que impulsionou a constituição e a consolidação de uma comunidade científica brasileira no campo da Informática Educativa.

Diversas outras iniciativas convergiram para a criação do primeiro Programa Nacional de Informática Educativa, o PRONINFE, em outubro de 1989, que visava fomentar o desenvolvimento da Informática Educativa nas escolas de $1^{\circ}, 2^{\circ}$ e $3^{\circ}$ graus e no ensino especial. $O$ foco central desse programa era impulsionar a pesquisa em Informática Educativa e desenvolver competência tecnológica concentrada em escolas técnicas e em universidades federais.

Em abril de 1997, com a evolução das iniciativas e do interesse pelo campo da Informática Educativa e com o fim da reserva de mercado instaurada pelos militares, ocorrido em 1992, o MEC lançou o Programa de Informática Educativa, o PROINFO. Tal programa teve como meta capacitar recursos humanos em 200 Núcleos de Tecnologia Educativa a serem criados em todo o Brasil e instalar 100 mil computadores em, pelo menos, 6 mil escolas da rede pública. A diretriz fundamental do PROINFO foi a 
mobilização de esforços para a introdução da tecnologia da informática no processo de ensino-aprendizagem nas escolas públicas de ensino fundamental e médio.

Em dezembro de 2010 foi implantado o Programa Um Computador por Aluno (UCA), proposto pelo Governo Federal como uma nova forma de utilização das tecnologias digitais nas escolas públicas brasileiras, balizada pela necessidade de melhoria da qualidade da educação, de inclusão digital e de inserção da cadeia produtiva brasileira no processo de fabricação e manutenção dos equipamentos. As ações previstas pelo projeto UCA se integram ao PROINFO do Ministério da Educação, com o aproveitamento das iniciativas e bases existentes de gestão e formação estruturadas nos núcleos estaduais e municipais de Tecnologia Educacional, descentralizados e distribuídos geograficamente, devendo se beneficiar das redes de formação de professores e dos núcleos de pesquisa em instituições de ensino superior.

Sempre dentro do escopo de ação do PROINFO, a mais recente ação no setor, no âmbito federal, consiste no Programa Tablets na Escola, que prevê a distribuição de 600 mil desses equipamentos a professores de todo o país, bem como o oferecimento de capacitações para seu uso adequado. A ideia do programa é disponibilizar um equipamento, com um conteúdo previamente definido, que dê acesso a revistas pedagógicas, jornais e livros digitais. O principal objetivo deste novo programa, que também prevê a compra e a distribuição de lousas digitais, é, tanto quanto todos os anteriores aqui citados, fazer com que os sistemas escolares acompanhem a evolução da sociedade no que se refere ao usufruto das possibilidades pedagógicas das mídias digitais.

O breve histórico aqui traçado nos permite observar que as TICE trazem em si, desde seu surgimento, a promessa de dinamizar a escola e de contribuir para o salto qualitativo rumo à Sociedade informacional. No 


\section{pesquisas}

entanto, apesar do cenário promissor desenhado por especialistas da área da Informática Educativa, essas tecnologias ainda não foram incorporadas à sala de aula e o embate em torno de sua premência e incontornabilidade tem movimentado milhões de reais e suscitado investimento intelectual de gerações de pesquisadores, sem que tenhamos chegado a um cenário minimamente promissor, tanto por causa da complexidade da questão, quanto por causa do gigantismo de qualquer política pública para o setor em um país com as dimensões do nosso. Isso sem se referir a nossos problemas crônicos de desigualdade social, de pobreza extrema, de distribuição de renda e de deterioração geral do ambiente da escola pública.

Apesar de todo o avanço teórico revelando as possibilidades de aplicação pedagógica das TICE, o novo paradigma educacional, necessário para criar o espaço de trabalho interdisciplinar, construtivista, dinâmico e multimediatizado por elas prometido, como uma quimera inatingível, permanece em construção. Enquanto isso, professores estão à deriva em toda parte. Pressionados pelas representações coletivas de que o uso da tecnologia corresponderia a uma espécie de redenção da educação, utilizam o computador reduzindo-o a um livro didático eletrônico ou a uma máquina de escrever digital. Assim sendo, a escola continua funcionando de maneira dicotomizada e ritualizada, respondendo à dinâmica da produção industrial, os currículos ainda são articulados em função de um tratamento disciplinar estanque, sequenciado, impondo um ritmo uniforme para o ensino e para a aprendizagem, supondo que os alunos aprenderão de maneira sincronizada conteúdos previamente estabelecidos, em momentos previamente determinados.

Por isso, entendemos que é preciso situar essas tentativas de apropriação pedagógica das tecnologias digitais em uma compreensão mais ampla desse movimento de modernidade e nos perguntamos: Como pensar, 
de fato, tais tecnologias na escola? E como pensar a escola com essas tecnologias? Como articular uma abordagem filosófica desse movimento de introdução das TICE no ambiente escolar, de modo que possamos melhor entendê-lo? E melhor entendê-las? Enfim, e sintetizando as demais questões, qual o papel da educação nessa Sociedade Informacional emergente? Foram estas questões que nos incitaram a avançar, de forma sistemática, em um empreendimento de natureza filosófica, suscetível de nos situar melhor diante da problemática, sempre pulsante, da apropriação pedagógica das novas tecnologias de informação, comunicação e expressão.

\section{Para a compreensão da escola em tempos de tecnologias digitais}

A Filosofia é uma disciplina intelectual que se serve de diferentes técnicas para a construção da compreensão do mundo. Para Platão, a filosofia tem um fim prático e este fim prático realiza-se, no entanto, intelectualmente, através da especulação, do conhecimento. A ciência busca recortar um conjunto homogêneo de fenômenos e reduzi-lo a uma matriz explicativa comum que possa ser confirmada ou impugnada pela comunidade científica. O produto dela é constituído por elementos explicativos dos fenômenos naturais ou sociais. A Filosofia, ao contrário, reúne várias correntes causais autônomas e heterogêneas, irredutíveis a princípios comuns e unificadas tão somente pelo resultado a obter. Sua preocupação é com o ato, que tem uma potência e uma concretude.

A abordagem filosófica, por mais simples que seja, não se resume à aplicação de um princípio científico único. Nenhuma arte ou técnica, a rigor, se deixa explicar totalmente pela ciência. A Filosofia tem sua racionalidade própria, com intersecções com a da ciência, mas não é redutível a ela. Enquanto que o resultado do trabalho científico é constituído por afirmações abstratas válidas para certo campo de conhecimento, o resultado da 


\section{pesquisas}

investigação filosófica é um produto concreto, obtido pela articulação real, não ideal, de diferentes articulações teóricas. A Filosofia não é um conjunto de afirmações abstratas sobre esta ou aquela parte da realidade, nem mesmo sobre a "realidade como um todo": é o empoderamento do sujeito para a compreensão da realidade objetiva, sem a qual nenhum conhecimento, qualquer que seja sua natureza, faz sentido. O método filosófico busca esclarecer a inteligibilidade, a significação e o real sentido dos conhecimentos e seus principais componentes são: a anamnese, pela qual o filósofo rastreia a origem das ideias; a meditação, pela qual ele busca transcender o círculo das suas ideias por meio de uma experiência cognitiva particular; a dialética, pela qual ele integra a sua experiência cognitiva na tradição filosófica, e esta naquela; a pesquisa erudita, pela qual o Filósofo se apossa da teoria do campo de conhecimento em estudo; a hermenêutica, pela qual ele torna transparentes para o exame dialético outras abordagens filosóficas sobre o mesmo objeto e todos os demais elementos da herança cultural que sejam necessários para a sua atividade filosófica; o exame de consciência, pelo qual ele integra as aquisições da sua investigação filosófica; e, finalmente, a expressão, pela qual ele compartilha sua experiência cognitiva com seus pares e com o mundo de modo geral.

Sobre a relação do conhecimento filosófico com a ciência, Bauer, Gaskell, Allum (2002, p. 17-360) retomam a seguinte tipologia dos interesses de conhecimentos, elaborada por Habermas: 1) empíricoanalíticas; 2) histórico-hermenêuticas e 3) críticas, significando, respectivamente, o interesse pelo controle técnico, a busca do consenso e a emancipação. Esses autores se associam, portanto, ao filósofo alemão, para apontar que as ciências empírico-analíticas têm como base seu interesse no controle técnico sobre a natureza e a sociedade; já as ciências históricohermenêuticas têm seu interesse prático no estabelecimento do consensoç 


\section{pesquisas}

quanto aos interesses emancipatórios, esses são atribuídos às ciências "críticas", as quais não excluem um modo de investigação empíricoanalítico, mas seu interesse vai além do entendimento hermenêutico.

Nossa perspectiva é de uma Filosofia de natureza predominantemente crítica e bibliográfica. Em outras áreas de conhecimento de caráter empírico, a pesquisa de campo recebe uma atenção especial e possui instrumentos e procedimentos próprios aliados à construção de um referencial teórico. Raramente em Filosofia existe a pesquisa de campo, deixando todo o foco sobre esse referencial teórico. Em Filosofia, os dados empíricos são válidos para justificar e exemplificar, mas não para fundamentar a argumentação. Então, há que se ter também rigor na concatenação das ideias, na coerência das conclusões e na discussão crítica, a fim de que o leitor possa também filosofar, indo além do que simplesmente apreender um conteúdo. Essa foi a abordagem metodológica que nos orientou na apreensão do conjunto de constructos teóricos indicados na seção seguinte e que nos permitiram construir um pensamento sobre o papel da educação na Sociedade Informacional, na perspectiva da integração pedagógica das mídias digitais. Essa abordagem, fruto de nosso trabalho investigativo de natureza filosófica, é apresentada a seguir. É inegável que a educação tem um papel crucial na constituição da Sociedade Informacional. De fato, é unicamente por meio da educação que teremos condições, enquanto indivíduos, de compreender e de nos situarmos na sociedade contemporânea, enquanto cidadãos partícipes e responsáveis. E as mídias digitais, a serviço da escola, devem ser compreendidas como elementos mediadores para a construção de uma nova representação da sociedade.

Geralmente, as discussões em torno das TICE e de sua influência na sociedade, em todos os setores e dimensões, se apoiam sobre uma certa exaltação deste tema, atribuindo-lhe praticamente o estatuto de novo 
paradigma fundamental, futuro regulador das interações sociais, culturais, éticas e profissionais numa nova sociedade que urge em tomar forma. Mas, qualquer que seja a ótica das discussões sobre o assunto, é inegável que a sociedade tem por base o mundo do trabalho, conforme a tipologia crítica que adotamos neste artigo.

\section{A questão do conhecimento no Século XXI}

A Filosofia não é mais a rainha das ciências, como nos ensina Chauí (1994) cuja imagem era de uma grande árvore frondosa, onde suas raízes eram a metafísica e a teologia, sendo o tronco a lógica, tendo por ramos principais a filosofia da natureza, a ética e a política e cujos extremos eram as técnicas, as artes e as invenções. No século XX, a filosofia foi submetida a uma grande limitação. Iniciada com Kant e seu questionamento sobre a razão, que foi considerada incapaz do conhecimento em si, posto que só poderíamos conhecer o que nos é factível pelos sentidos intelectuais.

$\mathrm{Na}$ atualidade, temos o capitalismo em crise, onde a produção e a posse do conhecimento tornam-se ser fatores determinantes. Marxistas e pós-modernos disputam sua apropriação e difusão. Enquanto os pósmodernos, como Lyotard (1989), defendem que a Ciência é feita por dissensos, é um jogo de linguagem onde vence o mais capaz de produzir algo rentável, competitivo e protegido por patentes, os marxistas argumentam que o conhecimento é intrinsecamente não apropriável, pois tem por base o trabalho social.

De acordo com Mattelart (2002), a referência ao termo "Sociedade da Informação" aparece subrepticiamente nos organismos internacionais (OIs) ou multilaterais após a década de 1970. Em 1975, a Organização de Cooperação e de Desenvolvimento para o Comércio (OCDE), estreia a noção e em 1979 usa o termo como palavra chave em um programa 


\section{pesquisas}

experimental: Forecasting and Assessment in the Field of Science and Technology, FAST, que inicia oficialmente em 1980. No campo das ideias, os OIs, incluindo o Banco Mundial, aderem ao debate do lado dos pósindustriais e pós-modernos o seu documento, publicado em 2003, Lifelong Learning in the Global Knowledge Econom (Aprendizagem Permanente na Economia Global do Conhecimento). Em seguida, o Banco Mundial propõe uma Metodologia de Avaliação do Conhecimento (KAM) (World Bank, 2014), por meio da qual se elaboram os Índices da Economia do Conhecimento (KEI). O KAM consiste em 81 variáveis estruturais quantitativas e qualitativas para 132 países, que servem para avaliar sua evolução nos 4 pilares da Economia da Informação, a saber: 1) incentivos econômicos e regime institucional, 2) educação, 3) inovação e 4) tecnologias da informação e comunicação. As variáveis são normalizadas em uma escala de 0 a 10 , relativas aos outros países no grupo de comparação. O conhecimento produzido se transforma, assim, em propriedade intelectual (PI). Para Dupas (2007) a propriedade intelectual, regulada por meio de um rígido controle da utilização de marcas e patentes, é um dos pilares do sistema de acumulação capitalista global.

Articulando PI com tecnologia, consideramos que essa última é fruto do trabalho humano, nela está contida e é a síntese do trabalho objetivado e transposto para as máquinas. A tecnologia não é outra coisa senão trabalho intelectual materializado dando visibilidade ao processo de conversão da ciência, potência espiritual, em potência material, traduzida e protegida por patentes e direitos autorais que têm mantido, como salientado por Saviani, Dupas e Mèzsáros, a hegemonia da classe social que detém o Capital na sociedade (MORAES,2010, p. 324).

A produção do conhecimento e da tecnologia dele decorrente não é, portanto, atividade neutra e envolve o dispêndio de um trabalho situado no 
tempo e no espaço, onde seus produtores ocupam uma posição de classe dominante no contexto da sociedade capitalista, interesse esse que tende a desprezar os interesses das classes trabalhadoras. A educação é, sem dúvida, o vetor principal dessa produção e de compartilhamento desse conhecimento e seu papel na sociedade Informacional emergente, subjacente à maioria dos programas governamentais brasileiros no campo da Informática na Educação, pelos efeitos inócuos que têm gerado em termos da alardeada promoção da emancipação dos sujeitos com eles envolvidos e por eles beneficiados, parecem estar ancorados na premissa de que o fator humano está a serviço da tecnologia e não o inverso. Essa submissão é claramente detectável na habitual falta de avaliação de um projeto, a fim de incorporar acertos e de eliminar erros na iniciativa seguinte, nas manipulações mercadológicas para vender tecnologia em detrimento das necessárias ações para formar cidadãos e na sistemática falta de articulação curricular em torno de projetos político-pedagógicos que promovam a formação de pessoas que usam a tecnologia ao invés de serem por ela usados. Em uma dimensão mais ampla, essa inversão de valores é imensamente evidente, posto que toda a tecnologia desenvolvida pela humanidade, as tecnologias digitais incluídas, não impede que o Século XXI seja apontado pelos próprios OI como o século da fome, da exclusão, da guerra tecnológica e da degradação ambiental irreversível, com uma Ciência para ricos e outra para os pobres.

Entretanto, Annan (2003, p. 1485) afirma que "a ideia de dois mundos científicos é um anátema ao espírito científico. A mudança desse cenário e a extensão dos benefícios da Ciência a todos exigirão o empenho dos cientistas e das instituições científicas em todo o mundo". E também, acrescentamos nós, dos organismos governamentais e não governamentais promotores e condutores de políticas públicas de acesso ao conhecimento, 


\section{pesquisas}

como no caso dos diversos projetos citados anteriormente. Nesse sentido, as palavras de Tilly (2006) são elucidativas: "Se considerarmos o acesso ao conhecimento científico benéfico a uma forma de liberdade, então a reserva desse conhecimento limita a liberdade no mundo" (p.48). Percebemos, então, que há uma encruzilhada teórica e política que demanda ação a qual, do ponto de vista teórico, passa por mais uma tentativa de compreensão do papel da educação na Sociedade Informacional emergente.

\section{Para a compreensão da educação na Sociedade Informacional}

Tomemos como ponto de partida, para nossa análise filosófica dessa problemática, autores do campo da sociologia contemporânea. Diversos deles (LYOTARD, 2006, GIDDENS, 1991; HARVEY, 1993) têm se debruçado sobre os rumos dessa Sociedade Informacional, situando-a, via de regra, no contexto da sociedade pós-moderna. O significado filosófico desse termo expressa a ideia de que estamos vivendo uma época que está nos levando para uma situação que não tem mais os mesmos apelos da modernidade, até mesmo por causa da saturação das tecnologias, de suas manifestações não necessariamente positivas na sociedade e do cenário social catastrófico anunciado para o século em curso. Para Guiraldelli Jr. (2000), os criadores da desconfiança pós-moderna foram Adorno, Horkheimer e Foucault. Adorno e Horkheimer escreveram Dialética do Iluminismo, livro que trata da "história da razão", argumentando que cada conquista da razão agrega o germe da desconfiança, num processo contínuo e crescente de autofagia. O Iluminismo - o trabalho da razão - é o processo de desmascaramento da ideologia e a impressão que por vezes se tem é de que avançamos, incólumes, em um emaranhado ideológico acerca da redenção educativa a ser trazida pelas tecnologias digitais, sem questioná-las e sem situá-las no âmbito da razão e da compreensão, o que 


\section{pesquisas}

seria natural, dado o nosso legado iluminista.

A ideia que queremos explorar é o absenteísmo quase universal de debatedores que trazem discursos contra hegemônicos, tanto no que se refere à implantação da Sociedade Informacional, quanto ao papel da educação a serviço dessa implantação e da constituição de uma sociedade ideal, como se fosse natural e óbvio. De fato, e de modo geral, observa-se que grande parte dos textos acadêmicos brasileiros apresenta uma visão acrítica desse conceito, sem empreender esforços para analisar a problemática ideológica nele envolvida. E o discurso ideológico está definitivamente presente nele, como argumentam Masson e Mainardes (2011), ao discorrerem sobre as entrelinhas da sociedade do conhecimento e suas implicações para a educação, subsidiária do mercado e não do Homem. Trata-se de uma falácia, posto que estamos ignorando o legado dos membros da Escola de Frankfurt, que, à semelhança de Marx, articularam a ideia de que o mundo moderno gera uma situação onde os humanos, que deveriam ser sujeitos, são na verdade os objetos, enquanto que os objetos, as coisas mortas, assumem a posição de coisas vivas. Este fenômeno é chamado de reificação.

A Escola de Frankfurt foi minando as bases da ideia de que o discurso da modernidade (iluminismo) tem a autoridade de um discurso com valor de verdade, mas a complexidade do mundo e a evolução feérica das coisas em detrimento da evolução tranquila do Homem nos impedem de vislumbrar, de pensar, de ver. A ideia que foi se formando é a de que o discurso contraideológico, por ser denunciador, é ameaçador e desestabilizador, o que não é uma verdade. Ele é complementar, orientador e necessário. Na linha de pensamento de Michel Foucault, a ênfase da filosofia, ao se debruçar sobre uma questão como a das tecnologias na escola, como discurso ideológico, deveria ser a construção de uma 


\section{pesquisas}

genealogia dessa questão para se aproximar do entendimento acerca de suas malhas (microfísica) para então se poder lidar com ela, controlar seu uso e ter plena consciência de suas consequências (FOUCAULT, 1979).

Se emprestarmos o pensamento de Lyotard (2006) para a análise da questão em pauta, notamos que a sequência de projetos de informatização do ensino público brasileiro, de tentativas, de tateamentos de se aproximar tecnologias e educação, nos coloca justamente em uma situação de construção de uma narrativa desconexa, à moda da pós-modernidade. A seu ver, estaríamos deixando de legitimar essa nossa narrativa coletiva que promove as tecnologias na educação por meio de metanarrativas, ou seja, por meio de grandes discursos filosóficos que a ampararia e a ela daria mais substância e possibilidades concretas de inclusão de todos e de consolidação de efeitos positivos para todos. Sempre a partir do pensamento de Foucault, não conseguimos tomar distância e analisar essa proposta de sociedade à luz da ideia de que o mercado funciona como uma "mão invisível" que organiza nossas vidas, como disse Adam Smith no século XVIII. Tampouco conseguimos manter em mente que história e lógica não estão em oposição. Na verdade, a História está casada com a Lógica, e o desdobramento da História, enquanto uma lógica, nada mais é que o desenvolvimento do espírito - enquanto sujeito ou enquanto cultura - que nos levará a graus maiores de liberdade, como disse Hegel na transição do século XVIII para o XIX.

Mas, esses grandes discursos (e outros) que estavam na base de todos os outros discursos, entraram sucessivamente em crise. Apareceu a desconfiança ou mesmo o descrédito completo nessas metanarrativas, e isso seria uma das características filosóficas principais da pós-modernidade, que nos mantém "blasés", condicionados pelos discursos majoritários e hegemônicos, por exemplo, pelo conteúdo das políticas públicas por trás de 


\section{pesquisas}

todos os projetos governamentais apresentados. Entretanto, mesmo com a ausência de narrativas explicativas ou alicerçantes, é claro o entendimento de que, qualquer que seja a configuração futura da sociedade, a intervenção do indivíduo para corroborar ou negar sua conformação, enquanto cidadão participativo e determinante em seu meio social continuará dependendo de sua posição no sistema de produção. Todavia, por enquanto não há nenhum indício empírico de que a sociedade informacional emergente será mais justa, mais prazerosa, mais democrática, mais igualitária.

No âmbito do processo de formação escolar, no sentido amplo do termo, a introdução de tecnologias digitais se manifesta segundo duas vertentes distintas, que indicam e delimitam o que nós consideramos como sendo a espinha dorsal da discussão em torno da inter-relação entre formação, cidadania e sociedade: o futuro do trabalho e a identificação do perfil do trabalhador em função da reestruturação do sistema produtivo. Por um lado, acredita-se que a automação dos processos de produção e a introdução de uma nova cultura tecnológica exigirá dos indivíduos uma formação qualitativamente mais ampla. Tal formação ampla torná-los-ia aptos para o desempenho de atividades integradas, o que os libertaria da rotina e da parcelização. Tendo em vista os constantes avanços tecnológicos e sua incorporação imediata nas empresas em função da busca pela qualidade total, condição para se manter no mercado, esta formação ampla procuraria introjetar em cada cidadão uma necessidade virtual e vital por autoformação continuada, condição para se manter no emprego. É a tese da requalificação, defendida, entre outros, por Naville (1956; 1972).

Por outro lado, crê-se que o discurso que advoga uma crescente qualificação da força de trabalho é um mito que faz parte e apoia a manutenção de um modelo de produção que preserva, em sua totalidade, o fetichismo da mercadoria e a alienação. A este respeito, Adorno e 


\section{pesquisas}

Horckeimer (1985) mencionam que o terreno no qual a técnica conquista seu poder sobre a sociedade é o poder que os economicamente mais fortes exercem sobre a sociedade. A racionalidade técnica hoje é a racionalidade da própria dominação. Ela é o caráter compulsivo da sociedade alienada em si mesma. Na mesma linha de pensamento, Chesneaux (1995) argumenta que juntamente com o mercado, o Estado se apodera do discurso das benesses das tecnologias na escola e, torna-se, além de seu cúmplice, o "seu exército". O pensamento de Michael Apple (1995), numa perspectiva próxima, sugere que a introdução de tecnologia nos processos humanos, como as tecnologias na educação das massas, não pode ser vista como um processo autônomo, independente das intenções sociais, do poder e do privilégio, mas situado na mesma vertente de sempre, de manutenção do status quo e, apenas, de preparação de mão de obra para uma nova etapa do capital. Moraes e Silva (2014) argumentam que, numa perspectiva contrahegemônica, Willians (2011) teoriza que os meios de comunicação são meios de produção e estão diretamente subordinados ao desenvolvimento histórico: “[...] das formas físicas mais simples da linguagem às formas mais avançadas da tecnologia da comunicação, são sempre social e materialmente produzidos e obviamente reproduzidos" (idem, p. 69). A partir de uma perspectiva socialista, do uso comunitário democrático, seria possível alcançar "de modo razoável e prático", o sentido dado por Marx ao comunismo como "a produção da forma mesma de comunicação", na qual, com o término da divisão do trabalho, dentro dos próprios meios de produção e de comunicação, os indivíduos falariam "como indivíduos", como seres humanos integrais (p.78).

A proposta de uma educação com as tecnologias de informação e comunicação, numa perspectiva contra-hegemônica à lógica privatista do capital, vem ao encontro à liberdade de uso de instrumentos por classes 


\section{pesquisas}

sociais que possam incorporar a sua sustentação política e não somente a atores favorecidos que se beneficiam no processo de apropriação do capital. Saviani (2007) tem razão quando postula que "[...] o dominado não se liberta se ele não vier a dominar aquilo que os dominantes dominam. Então, dominar o que os dominantes dominam é condição de libertação" (SAVIANI, 2007, p. 55), como vimos recentemente na visibilidade mundial, inclusive no Brasil, dada à exploração das redes sociais, manifestação mais abrangente das tecnologias digitais, para fomentar a mobilização em torno de diversas causas de interesse popular, desde oposições a governos na Tunísia, na Síria, no Egito, na Venezuela, na Ucrânia, passando por demandas contra um sacrifício de uma girafa em um zoológico na Dinamarca, até reivindicações contra a realização da Copa do Mundo e em prol da mobilidade urbana, no Brasil.

Então, que tipo de educação os aparatos tecnológicos que se quer na escola deveriam promover? Avançando, concomitantemente, em um movimento de acesso a um quadro teórico que subsidia a discussão em foco (anamnese), de reflexão sobre a pertinência desse quadro teórico (meditação), de investimento do mesmo na compreensão de nossa realidade objetiva (dialética) e de interpretação dessa última à luz de nossos objetivos de investigação (hermenêutica), passemos às últimas etapas dessa nossa reflexão, o exame de consciência e a expressão, tendo em vista que o método filosófico tem uma natureza eminentemente prática.

\section{À guisa de conclusão}

Nosso esforço teórico, resumido e apresentado nesse texto, constitui-se em uma tentativa de compreensão mais ampla desse movimento de pósmodernidade que é a apropriação pedagógica das tecnologias digitais. As seguintes questões nortearam o estudo: Como articular uma abordagem 


\section{pesquisas}

filosófica desse movimento de introdução das TICE na escola, de modo que possamos melhor entendê-lo? E, mais amplamente, como compreender e situar a educação nessa Sociedade Informacional emergente?

Ora, sabe-se que a tecnologia é fruto do trabalho humano. Nela está contida a síntese do trabalho objetivado transposto para as máquinas, conforme debate Moraes (2010). Logo, a utilização das TICE na escola só poderá propiciar uma aprendizagem emancipatória e democrática, no sentido iluminista desses termos, se e somente se estiver articulada com um projeto político-pedagógico igualmente emancipatório, realmente inovador e que seja aberto à análise crítica por parte de todos os cidadãos, o que nem está presente nas políticas públicas que emolduram os projetos apresentados, nem ao alcance de nossos cidadãos, dadas as limitações educacionais a que são historicamente submetidos.

Ao contrário de Atenas, que tinha escravos que não se manifestavam sobre os destinos da sociedade, hoje temos a Internet e as redes sociais que facilitam em muito esse processo emancipatório e que têm levado a patamares inimagináveis o nosso poder de comunicação e expressão, bem como o valor da informação. Mas, ações amplas de inclusão digital e de oferecimento de uma educação para as mídias são imprescindíveis para propiciar esse uso. No entanto, a escola, tradicional locus de "transmissão" do saber às novas gerações e principal ambiente para seu empoderamento, tem seu papel bastante diluído justamente por causa da emergência das tecnologias digitais, que permitem e potencializam as necessidades e as capacidades humanas de aprender, de se informar e de comunicar sem a escola. Vemos aí um movimento de pós-modernidade que recoloca o paradigma educacional na modernidade, e põe em cheque o seu caráter universalista e monolítico. A busca por um modelo de escola que integre as tecnologias digitais, por meio dos sucessivos programas governamentais 


\section{pesquisas}

apresentados no início deste texto, revela que existe a compreensão clara, por parte do poder público, de que nossa tradicional forma de interação com o conhecimento e de formação para o exercício da cidadania está em mutação tão irreversível quanto há cinco séculos atrás quando o ser humano começou a se libertar da limitação física da cultura manuscrita. Tal irreversibilidade deve-se, sobretudo, ao advento dessas tecnologias. Mas, apesar dessa compreensão, tão eloquentemente alardeada os discursos governamentais, não há práticas efetivas para sua implantação nos currículo e para sua efetivação na educação escolar que oferecemos a nossas crianças e jovens.

Mas, onde está e para onde vai a escola nessa turbulência toda? Segundo Afira Ripper, pesquisadora da Universidade Estadual de Campinas (1995), a escola, como lugar onde se formaliza a aquisição de conhecimentos pela nova geração não sofreu, ao longo dos tempos, transformações radicais quanto à forma como eles são colocados à disposição dos alunos. Enquanto a sociedade como um todo criou novas formas, ou mídias, de armazenar e transmitir o saber, a escola parece cega, surda e muda às metamorfoses da percepção humana que a realidade tecnológica está provocando. A escola encara a formação da percepção, da sensibilidade e da subjetividade de seus alunos como se eles ainda se encontrassem no século XVII, antes da Revolução Industrial. De fato, não é mais adequado continuar concebendo o processo de ensinar como sendo sinônimo de transmissão do saber de maneira dogmática, verbalística, repetitiva, onde o professor é visto como detentor de todo saber, centro do processo de aprendizagem, mas «migrar» para abordagens centradas na busca de informações, na revisão da própria experiência, na aquisição de habilidades, na adaptação às mudanças, na descoberta de significados nos seres, fatos e acontecimentos. E nenhum movimento de introdução de meios 
digitais na educação nos sinalizou ainda com modificações efetivas e permanentes prol de uma educação socialmente responsável e cidadã, conforme argumentam Moraes e Silva (2014)

A nosso ver, para que isso ocorra são necessárias ações multidirecionadas, que conjuguem tanto os "de baixo", nas palavras do saudoso Florestan Fernandes (1994), como os de cima, a saber, os responsáveis pela elaboração e execução das políticas públicas, pois de outra forma, continuaremos investindo recursos que serão ineficazes para os que estão na base da pirâmide social e, consequentemente, aumentando o fosso que separa ricos e pobres, agora materializados nos infoexcluídos. Se aceitarmos e nos situarmos na perspectiva da Sociedade Informacional, devemos reivindicar uma escola que seja vetor de ampla e irrestrita inclusão digital, em todos os sentidos do termo, o que vai muito além da concessão de acessos a aparatos técnicos, mas de permitir o trânsito de todos na Ágora, que agora é cibernética e digital, bem como preparar os indivíduos para atuarem nessa nova realidade, tanto de modo empírico, quanto teórico e virtual.

\section{Referências}

ADORNO, T. W.; HORCKHEIMER; M. Dialética do Esclarecimento. Fragmentos Filosóficos. Rio de Janeiro. Zahar Editor, 1994.

BAUER, M. W.; GASKELL, G; ALLUM, N. C. Qualidade, Quantidade e Interesses do Conhecimento. Evitando Confusões. In: BAUER, M W.; GASKELL, G (org.) Pesquisa Qualitativa com texto, imagem e som. Um manual prático. Petrópolis: Vozes, 2002, p. 17-36.

CHAUI, M. Convite à Filosofia. São Paulo. Ática, 1994.

CHESNEAUX, J. Modernidade-Mundo. Petrópolis: Vozes, 1994.

FERNANDES, F. Democracia e Desenvolvimento: a transformação da periferia e 
capitalismo monopolista na era atual. São Paulo: Hucitec, 1994.

FOUCAULT, M. Microfísica do poder. Organização e tradução de Roberto Machado. Rio de Janeiro: Edições Graal, 1979.

GHIRALDELLI JR., Paulo. A teoria educacional no Ocidente: entre modernidade e pós-modernidade. São Paulo Perspec., Jun 2000.

GUIDDENS, A. (1998). Politica, Sociologia e Teoria Social: Encontros com o Pensamento Social Clássico e Contemporâneo. São Paulo: UNESP.

HARVEY, D. A Condição Pós-Moderna. São Paulo: Loyola, 1989.

LACERDA SANTOS, G. O uso da teleinformática na atualização científica e tecnológica de professores da rede federal de ensino técnico no Brasil: a participação de todos na formação continuada à distância de cada um. Anais do Congresso Anual da Rede Iberoamericana de Informática Educativa, 1996. Acessado em 11/03/2014 em: <http://lsm.dei.uc.pt/ribie/docfiles/txt200352145518O $\% 20$ uso $\% 20$ da $\% 20$ teleinform $\%$ C3\%A1tica.pdf.>

LETTI, M. A escola precisa estudar. Revista Digital Sala. Texto acessado em 05/03/2014 em: <http://www.sala.org.br/index.php/estante/colunas/educarna-cultura-digital/943-a-escola-que-precisa-estudar>

LYOTARD, J. F. A condição pós-moderna. Trad. Ricardo Corrêa Barbosa. São Paulo: Loyola, 2006.

MASSON, G. e MAINARDES, J.. A ideologia da sociedade do conhecimento e suas implicações para a educação. Currículo sem Fronteiras, v.11, n.2, pp.70-85, Jul/Dez 2011. Acessado em 10/03/2014 em: $<$ http://www.curriculosemfronteiras.org/vol11iss2articles/massonmainardes.pdf. $>$.

MATTELART, A. História da Sociedade da Informação. São Paulo: Loyola, 2002. MORAES, R. A; SILVA, R. G. Virtualidade e educação a distância em educação em pós-graduação: o blended learning em questão. In: XII Taller 
Internacional Junta Consultiva sobre el postgrado en Iberoamerica, 2014, La Havana. Universidad 2014 - 9vo Congreso Internacional de Educacion Superior. La Havana: Ministerio de Educacion Superior, 2014. v. 1. p. 1-10.

MORAES, R. A. Institucionalização da EaD nas IES públicas: uma perspectiva histórico-crítica e emancipadora. In: Daniel Mill; Nara Pimentel. (Org.). Educação a Distância: desafios contemporâneos. 1 ed. São Carlos: EdUFSCar, 2010, v. 1, p. 319-349.

RIPP RIPPER, A, V. O Computador chega à escola. Para quê? In: Revista Tecnologia Educacional. São Paulo, 1995, pp. 40-43.

SAVIANI, D. Pedagogia Histórico-Crítica: primeiras aproximações.8a. ed. Autores Associados, 2003.

TAPSCOTT, D. Economia digital: promessa e perigo na era da inteligência em rede, São Paulo; Makron Books, 1997.

WILLIANS, R. Cultura e Materialismo. São Paulo: Editora Unesp, 2011.

WORLD BANK. Knowledge Assessment Methodology, KAM. 12 Disponível em:

<http://web.worldbank.org/WBSITE/EXTERNAL/WBI/WBIPROGRAM S/KFDLP/EXTUNIKAM/0,,menuPK:1414738 pagePK:64168427 piPK:6 4168435 theSitePK:1414721,00.html> Acesso em 21/12/12.

WORLD BANK. Lifelong Learning in the Global Knowledge Economy. Challenges for Developing Countries. Washington: World Bank, 2003. Disponível em $<$ http://tinyurl.com/azkpdnq> Acesso em 21/12/12. 